\title{
Customer Ownership of the Local Loop: A Solution to the Problem of Interconnection
}

\author{
P.B. Schechter ${ }^{1}$ \\ Interdisciplinary Telecommunications Program \\ Campus Box 530 \\ University of Colorado \\ Boulder, CO 80309 \\ Voice: 303/320-0778 \\ Fax: 303/270-5886 \\ e-mail: pb@Colorado.edu
}

To be published in Telecommunications Policy, October, 1996.

${ }^{1}$ Current address: Colorado AHEC Program, University of Colorado Health Sciences Center, 4200 East Ninth Avenue, Campus Box A096, Denver, CO 80262 


\begin{abstract}
Interconnection is necessary for competition in telephony, but interconnection agreements are difficult to negotiate. With local service competition, entrants usually cannot duplicate the local loop, so interconnection also involves "renting" the incumbent's local loops. An incumbent may object to being asked to permit use of its infrastructure by its competitors, in order to allow its competitors to compete with it. If customers own their local loops, however, the problems of interconnection virtually disappear: customers will determine whose traffic their loops carry, and incumbents will not have to supply competitors with the means of competing with them.
\end{abstract}

Running Title: Customer Ownership of the Local Loop

Acknowledgements: I thank J im Alleman, Dale Hatfield, Sandy McCray and Vince Snowberger for helpful comments on earlier versions of this paper. 


\section{Introduction}

In order for competition in telephony to exist, there must be multiple service providers; in order for competition in telephony to be successful, the multiple service providers must interconnect with each other, to form a network that appears seamless to customers. Interconnection among competing providers of local telephony, however, has become a nearly intractable problem, because the interconnecting parties are typically of two very different types. One is the incumbent, who used to be a monopoly service provider, and who owns a complete infrastructure. The other is the competitive entrants, who wish to provide service in competition with the incumbent, but who are forced to use at least part of the incumbent's infrastructure - namely, the local loops-because constructing a complete infrastructure is prohibitively expensive.

The situation, thus, is as follows: an entrant constructs a limited infrastructureperhaps in the downtown business area-and then seeks to interconnect with the incumbent, so that its customers may place calls to, and receive calls from, everyone's customers. The interconnection that the entrant seeks, however, appears especially insidious to the incumbent: the entrant wishes to, in effect, "rent" the local loops of the incumbent's customers-in order to compete with the incumbent! In fact, the incumbent must rent the local loops of the entrant's customers, as well. But this mutual renting of one's competitor's local loops is asymmetrical: the incumbent has far more customers than the entrant and, therefore, the entrant has far more to gain than the incumbent-and the incumbent has far more to lose than the entrant-by interconnecting their respective networks.

It is, therefore, not surprising that it is rare for an incumbent and a competitive entrant to agree on interconnection terms: It is in the incumbent's self-interest to refuse to interconnect at all, or to charge such a high price that the entrant cannot successfully compete. It is in the entrant's self-interest to obtain interconnection for nothing, or, at least, for less than the cost of building and maintaining its own local loops. On the one hand: 
The modern precedent and practice in competitive telecommunications interconnection had become established [by AT\&T's behavior with respect to $\mathrm{MCl}$ 's requests for interconnection, in the U.S., in the 1970s], namely: (i) the incumbent monopolist or dominant carrier will invariably act in an exclusionary manner towards the new entrant; (ii) normal commercial negotiations between the parties will break down, requiring intervention by the regulator or legislature. $^{2}$

On the other hand:

... the most contentious issue throughout [negotiation between the incumbent and a competitive entrant in New Zealand] was price. No competitor wants to pay more for interconnection than anyone else and preferably nothing at all....

It is just that ... there is always the opportunity for public grandstanding. The points of interconnection issue was clouded by this kind of unproductive and almost mischievious [sic] behavior. $^{3}$

No consensus exists concerning the proper charge for interconnection. Indeed, analysis of the assumptions underlying the need for interconnection leads one to conclude that pricing interconnection is a dilemma: one can either be unfair to the incumbent or unfair to the entrant, but not clearly, simultaneously, fair to both.

This paper argues that if customers own their local loops, the interconnection dilemma is circumvented, and the problems for determining a fair interconnection scheme virtually disappear. The remainder of this paper is organized as follows: First, the paper briefly reviews some of the schemes that have been proposed to price interconnection. It discusses some advantages and disadvantages of these schemes, and shows that none truly solves the problem of interconnection. Then, the paper explains the notion of customer ownership of the local loop, considers some potential problems with such an arrangement, and demonstrates that this is, truly, a solution to the problem of interconnection.

${ }^{2}$ Walker, D. \& Solomon, J . "The Interconnection Imperative: E pluribus unum.” Telecommunications Policy, 17(4), 1993, p. 260.

3Saunders, M. "Telecommunications Regulation in New Zealand." Telecommunications Policy 18(6), 1994, pp. 495-496. 


\section{Proposed Solutions to the Problem of Interconnection}

There are two types of interconnection that are both common and relatively noncontroversial: interconnection between inter-exchange ("Iong distance") carriers (IXCS) and local exchange carriers (LECS), and interconnection between carriers of international traffic. The reason these arrangements are common and non-controversial is that they are both cases of interconnection between providers of complementary, rather than competing, services. In creating competition in local telephony, of course, the goal is for customers to have choice in their service providers-which requires interconnection among providers of competing services. It is in these situations that interconnection has proven difficult.

Once interconnection is agreed upon-or mandated by regulators-the problem is to price it fairly. It is clear that an incumbent is entitled to some payment for the use of its network, and it is equally clear that the amount of that payment can have crucial consequences for the success of competition. On the one hand, an incumbent can price competition so high that the costs of the competitive entrant are higher than those of the incumbent. The entrant will then be forced to price its service higher than the incumbent's, and it is unlikely that such an entrant will be successful. On the other hand, interconnection can be priced so low that the entrant does not pay the full cost of that interconnection. In this case, the incumbent will be unable to compete with the entrant, and there will be no incentive for the entrant to build its own network, since it can use the incumbent's for less than the cost of building its own. ${ }^{4}$

Clearly, the ideal is for interconnection to be priced at cost. Then, if an entrant is more efficient than the incumbent, it will gain market share by passing on that efficiency to its customers, in the form of lower prices. If, on the other hand, the incumbent is more efficient

\footnotetext{
${ }^{4}$ In the long run, of course, this is not tenable: barring subsidies, the entrant will capture the entire market, the incumbent will fail, and the entrant will have to acquire - through construction or through purchase- the infrastructure that it leased from the failed incumbent.
} 
and can provide comparable service at a lower price, then it is perfectly appropriate-from the economist's and the consumer's points of view-for the incumbent to succeed and the entrant to fail. The problem, of course, is knowing just what that perfect price for interconnection is.

\subsection{The Efficient Component Pricing Rule}

The efficient component-pricing rule (ECPR), which has been used to price interconnection in both Illinois and N ew Zealand, ${ }^{5}$ states that "the price of an input should equal its average-incremental cost, including all pertinent incremental opportunity costs." ${ }^{\prime 6}$ In this case, the "input" is the local loop, the competitor is the competitive entrant, the average incremental cost is the actual cost to the incumbent of carrying the entrant's traffic on its network (this is probably near zero, in the telecommunication world, so long as the entrant's traffic uses otherwise excess capacity), and the incremental opportunity costs are the revenue that the incumbent loses by having the entrant capture part of its market (this may be greatly in excess of zero, in the telecommunication world). The main goals of the ECPR are (1) to avoid inefficient entry; and (2) to create a situation in which the incumbent is indifferent as to whether it sells its intermediate good to a competitor or to a retail customer.

The ECPR has been criticized for a variety of reasons, both theoretical and practical. ${ }^{7}$ However, one of the most striking reasons for skepticism concerning its appropriateness is provided by Baumol himself, in testimony before the New York State Public Service Commission (the "parity pricing rule" is another name for the ECPR):

${ }^{5}$ Baumol, W.J . \& Sidak, J .G. Toward Competition in Local Telephony. Cambridge, MA: The MIT Press. 1994.

${ }^{6}$ Baumol, W.J . \& Sidak, J.G. "The Pricing of Inputs Sold to Competitors." The Yale J ournal on Regulation, 11(1), 1994, p. 178.

7See, for example, Albon, R. "Interconnection Pricing: An Analysis of the Efficient Component Pricing Rule." Telecommunications Policy 18(5), 1994, pp. 414-420; Economides, N. and White, L.J. Access and Interconnection Pricing: How Efficient is "Efficient Component Pricing Rule'?" Antitrust Bulletin, 40(3), 1995, pp. 557-579. Laffont, J .-J . and Tirole, J . 1995. "Creating Competition Through Interconnection: Theory and Practice." Paper presented at International Telecommunications Society Interconnection Workshop, 10-12 April 1995, Wellington, N.Z; Schechter, P.B. "Telecommunication in New Zealand: Competition, Contestability and Interconnection." Submitted to Pacific Telecommunication Review. 
Q: Would you consider the price of access permitted by the parity pricing rule to be inadequate or generous from the point of view of the provider of access to bottleneck facilities?

A: The price of access under the parity principle is clearly extremely generous to the LEC, because it permits the owner of the facilities, in this case the LEC, to earn from the access user a profit equal to the full profit that the LEC earns on the bundled combination of access and message transport when it sells the final toll-service product to the ultimate customer. In other words, it offers the LEC a profit on access alone, when sold to an IXC equal to the profit the LEC earns on the two services of access and transport together, when it itself supplies final product.

Indeed, the parity principle is so generous to the owners of the bottleneck that in other regulatory arenas it has been opposed vigorously by purchasers of access. ${ }^{8}$

And careful consideration leads one to the conclusion that interconnection pricing, in the framework of the ECPR, is truly a dilemma: On the one hand, it is reasonable, and standard business practice, for an incumbent that owns its infrastructure to be entitled to a price for interconnection that is equal to its cost of carrying the entrant's traffic plus its lost opportunity cost for doing so. (This is, of course, the efficient component-pricing rule.) On the other hand, however, the ECPR means that the incumbent is entitled to treat a competitive entrant exactly as it would treat any other ("retail") customer. And it would be extremely difficult, under these conditions, for a competitive entrant to succeed. F or, in order to successfully compete with the incumbent, an entrant must be able to offer at least the same service for the same price (typically, it will have to offer the same service for a lower price, or superior service for the same price). And, if the entrant is paying both the incremental cost and the opportunity cost ("profit") of the incumbent's part of its service, then in order for the entrant to price its total service at or below the incumbent's price, it will have to have costs that are enough below the incumbent's to offset the opportunity cost that it must pay the incumbent-and, of course, pass on to its customers.

${ }^{8}$ Baumol, W.J . "Direct Testimony of William J . Baumol of Behalf of AT\&T." Case 92-C-0665, 1994. 


\subsection{The ECPR With Global Price Caps}

Recently, a system of "global price caps" has been proposed. ${ }^{9}$ According to this proposal, intermediate goods-such as interconnection-are considered as final goods in that they are included in a single basket, subject to price cap regulation. Global price caps, then, in combination with the Efficient Component Pricing Rule, might be better than the ECPR alone at determining an appropriate cost for interconnection. The reason for the improvement of global price caps plus the ECPR over the ECPR al one is that, with global price caps, there is no need for knowledge-by a regulator or a competitor - of the actual cost of interconnection, because interconnection is in a single price basket al ong with its retail service. Since raising the price of interconnection would require lowering the price of some other element in the basket, the incumbent has a negative incentive to set the price of interconnection arbitrarily high.

\subsection{Bill and Keep}

Another method of pricing interconnection that escapes the framework of the ECPR dilemma is sometimes called "bill and keep." According to this method, all companies interconnect, call originators are billed for calls, and the originating company keeps all money collected. This seems intuitively fair, since the company with the largest number of subscribers (and, presumably, the largest network) will likely be the same company on which the largest number of calls originate-and, therefore, the company that will keep most of the revenue. This scheme has been argued for recently, using the Internet as a model. The Internet, according to this argument, has developed in a free, unregulated market, and has adopted the bill and keep method of pricing interconnection. If telephony had developed in a similarly free market, the argument continues, it would have evolved toward bill and keep, as

${ }^{9}$ Laffont, J.-J . and Tirole, J . Op. cit.. 
well. ${ }^{10}$

A major argument against bill and keep is, of course, that it treats incumbents and competitive entrants more or less as equals. However, incumbents-perhaps because they have larger infrastructures and larger customer bases-typically believe than an entrant receives far more value from interconnection than does the incumbent; the entrant, incumbents therefore believe, should pay far more for interconnection than should the incumbent. Such an argument has recently been made against using bill and keep to price interconnection between cellular service providers and wireline service providers. ${ }^{11}$

\subsection{Various Ad Hoc Schemes}

There have also been a variety of proposals of ad hoc "rules" or "principles," that are intended to solve the problem of interconnection. These include suggestions such as submitting negotiations to binding arbitration if an agreement cannot be reached within a specified number of days, ${ }^{12}$ admonitions for "efficient" responses to requests for interconnection, ${ }^{13}$ and using the "half-call" concept, whereby LECs charge each other for call termination about 50\% of what they charge their (retail) end users. ${ }^{14}$

\footnotetext{
${ }^{10}$ Brock, G.W. "Interconnection and Mutual Compensation With Partial Competition." In The Economics of Interconnection, Tel eport Communications Group, 1995.

${ }^{11}$ Rohlfs, J .S., Shooshan, H.M. III \& Monson, C.S. "Bill-and-Keep: A Bad Solution to a Non-Problem." Filed before the Federal Communications Commission, In the Matter of Interconnection Between Local Exchange Carriers and Commercial Mobile Radio Service Providers (CC Docket No. 95-185) and Equal Access and Interconnection Obligations Pertaining to Commercial Mobile Radio Service Providers (CC Docket No. 94-54), Attachment to the Comments of the United States Telephone Association, March 4, 1996. Available at http://www.spri.com/reports/publist.htm.

${ }^{12}$ Patterson, R., Savin, B. and Davies, M. “Light-Handed Regulation of Telecommunications in New Zealand: The New Frontier?" Paper presented at International Telecommunications Society Interconnection Workshop, 10-12 April 1995, Wellington, N.Z.

${ }^{13}$ Grieve, W. \& Levin, S. L. "Economic Principles and Pricing Rules for Local Network Interconnection and Network Component Unbundling With Applications for New Zealand." Paper presented at International Telecommunications Society Interconnection Workshop, 10-12 April 1995, Wellington, N.Z.

${ }^{14}$ MFS Communications Co., Inc. has negotiated interconnection agreements with NYNEX (“NYNEX, MFS Announce New York Interconnection Plan." Telecommunications Reports, J anuary 30, 1995) and Pacific Bell ("MFS Signs Interconnection Pact With Pacific Bell." Telecommunications Reports November 27, 1995) using the half-call concept to price interconnection. MFS's President considers half-call pricing a "transitional mechanism," that should eventually be replaced by a more cost-based pricing mechanism.
} 
Such proposals have the advantage that they are often simple to implement, in part because they are likely to be agreeable to reasonable people, at least in principle. However, the suggestions have no principled foundation: these proposals provide no basis upon which an arbitrator is to make a decision—other than "compromise." In general, it is preferable to trust objective principles_to which even people of less than good faith can be held-than subjective "rules of thumb," whose application—even by people of good faith—is readily subject to honest disagreements, misunderstandings, and differences of opinion.

\section{Customer Ownership of the Local Loop}

There is a straightforward solution to the dilemma of interconnection pricing: customers should own their local loops. If customers own their local loops, it is clearly they al one who have the right to decide which LEC should originate and terminate their traffic, on their local loop. Interconnection among competing local service providers would still, of course, be necessary. However, it should be simple for companies to negotiate, or for regulators to mandate, its terms and conditions. For, when customers own their local loops, service providers negotiate from relatively symmetrical positions: each provides service to its customers, but none is required to rent the use of its competitor's bottleneck facility—from its competitor - at a price that includes its competitor's monopoly rent; or, none is required to rent the use of its bottleneck facility to a competitor, at a price that does not cover the large embedded cost of constructing that bottleneck facility.

In more detail, if customers own their local loops, service providers will probably need to interconnect at two places: the frame, and the trunk side of the switch. In the former case, the "interconnection" is merely the running of wires from the positions on the frame where LEC A's customers' local loops terminate to LEC A's switch, and the running of wires from the positions on the frame where LEC B's customers' local loops terminate to LEC B's switch. The additional costs due to this "interconnection" are minimal; the frame becomes a jointlyowned piece of hardware. 
Interconnection will be desirable at the trunk side of the switch because LEC A's customers will, presumably, want to place calls to LEC B's customers (and, of course, vice versa); the former are served by LEC A's switch, and the latter are served by LEC B's switch. In this case, there is a non-zero additional cost for interconnection, but it is not high: it is no more than the cost to a LEC of adding an additional central office to its (local) network. Here, again, it seems reasonable to share the cost of interconnection among the LECS involved..$^{15}$

The issue of paying for the cost of terminating calls on a competitor's network should disappear, because that cost-once the construction and maintenance of the local loop is removed-is virtually zero. Or, even if it is not zero, it is probably considerably less than the cost of billing such call termination. This is similar to the argument for the "bill and keep" method of pricing interconnection. However, when customers own their local loops, incumbents have less justification for arguing that they are providing more value to their competitors than they receive from them, because it is the customers themselves, rather than the LECS, that are "providing" the local loops for call termination.

There are additional advantages of customers owning their local loops. They include the likelihood of the creation of a competitive loop construction industry, the ability of exactly those customers who value high capacity loops to purchase those loops, the elimination of a large portion of the cost of entry into provision of local telephone service, the elimination of most of the problems of the transition from a regulated monopoly to market competition, and elimination of the need to use traffic sensitive metrics to allocate costs of non-traffic sensitive portions of the network. These issues are beyond the scope of this paper; they are dealt with

\footnotetext{
${ }^{15}$ It is possible to argue that the entrant should bear the entire cost of this interconnection, since it is the entrant that is entering the market, and, therefore, the entrant that causes the additional cost of interconnection. Such an argument assumes that the incumbent is somehow entitled to its (current) monopoly position, and that the entrant should pay for any changes from this natural entitlement. However, even if the entrant is required to pay the entire cost of interconnection, it is unlikely that the cost will be high.
} 
elsewhere. ${ }^{16}$

\section{Potential Problems With Customer Ownership of the Local Loop}

This section considers several potential problems with customer ownership of the local loop. It shows that, upon closer inspection, each problem is either not particular to customer ownership of the local loop, or easily surmountable, or both.

\subsection{Cost}

Probably the first problem that comes to mind when considering the proposal that customers should own their local loops is cost: if it is prohibitively expensive for a competitive entrant to own (that is, to build and own) the local loops, why is it less expensive for customers to do so? The answer, of course, is that no customer need own more than a single local loop-his or her own. Estimates of the cost of local loops vary-in part because of different assumptions and methodologies involved in those estimates. An upper limit estimate is obtained by dividing the total book value of LEC plant (about $\$ 250$ billion) by the total number of access lines (about 150 million), which is $\$ 1,700$. However, only about $60 \%$ of this plant is used for local loops, so the average value of a local loop is about $\$ 1,000 .{ }^{17}$ Estimates based on new construction, using modern technology, suggest an average cost of about $\$ 700$ per local loop. ${ }^{18} \mathrm{~A}$ more recent study estimates that if a new network were to be built, using the most modern technology, with an expected life of 18 years, the average monthly cost of providing basic residential service-not merely loop construction cost-would be approximately $\$ 21.30 .{ }^{19}$ If a customer finances $\$ 1,000$ for ten years at $7 \% A P R$, the monthly payments would be about $\$ 11.60$ (financing $\$ 700$ for ten years would result in monthly payments

\footnotetext{
${ }^{16}$ Schechter, P. B. "Customer Ownership of the Local Loop: Its Effects on Competition in Telephony." To be presented at the Eleventh World Conference of the International Telecommunications Society, J une, 1996.

${ }^{17}$ Arellano, M. “Exploiting the LECs' Achilles' Heel." Telecom Strategy Letter, J uly, 1995, p. 83.

${ }^{18}$ Reed, D.P. Residential Fiber Optic Networks: An Enginering and Economic Analysis. Norwood, MA: Artech House, pp. 288-289.

${ }^{19}$ This is calculated from data in a study by Hatfield Associates, Inc. "The Cost of Basic Universal Service." J uly, 1994, Table 2, p. 4.
} 
just under \$8.10); the median annual household income in the U.S., in March, 1994, was $\$ 31,241 .{ }^{20}$ If there are people who would like tel ephone service but who cannot afford $\$ 21.30$ per month, it is reasonable to expect the state to subsidize telephone service just the way it subsidizes housing, food, medical care and education-if telephone service is considered a similar necessity.

This is, of course, the issue of universal service It is no more an issue when customers own the local loops than when LECs own them. Indeed, it may be less of an issue with customer ownership of the local loop. This is because the local loop is the dominant cost of providing local telephone service - the local loop accounts for approximately $60 \%$ of US West's costs $^{21}$ and a comparable portion of the total book value of the LECs' plant; ${ }^{22}$ customer ownership of the local loop makes that cost, and that dominance, explicit. Thus, if customers own their local loops, it is sensible for subsidies—if any—-to be provided directly for construction of those local loops. In such a scenario, it is likely to be generally less acceptable than in the current one, to provide subsidies to wealthy households whose inhabitants choose to live in high cost areas. $^{23}$

\subsection{What Should Incumbents Do With Obsolete Infrastructure?}

If customers own their local loops, it is likely that local loop construction will become a competitive industry. Those customers who are satisfied with the copper loops provided by the incumbent will, presumably, purchase their existing loops; those customers who value fiber, coaxial or radio local loops will, presumably arrange to have such loops constructed-by the incumbent, or by any other company with the desire and ability to do so. This raises the

${ }^{20}$ U.S. Bureau of the Census, Statistical Abstract of the United States: 1995 (115th edition.) Washington, D.C., 1995, p. 473. tion.

${ }^{21}$ Brian J ohnson (Director of Colorado Regulatory Affairs, US West Communications), personal communica-

${ }^{22}$ Arellano, M. op. cit..

${ }^{23}$ It is also likely, in a world where customers own their local loops, that creative financing methods will emerge-much as they have done in the real estate market. 
question of what the incumbent should do about the local loops that it must abandon because customers choose not to purchase them. This is an issue of fairness: regulators have set long depreciation schedules for local loops in order to maintain service rates and to increase telephone penetration, but now, suddenly, loops that have not been fully depreciated (i.e, loops whose construction cost has not been fully recovered) have no value; their construction cost will never be fully recovered.

In considering this issue, it is important to realize first, that the problem is limited to those loops that have not been fully depreciated; and second, that it exists only to the extent that regulators have forced incumbents to use long depreciation schedules. The problem is limited to undepreciated loops, of course, because regulated companies recover capital costs by depreciating them over time. The problem is tied to regulation because if regulators have not mandated long depreciation schedules, then incumbents have faced exactly the same decision faced by unregulated companies: they have had to find a price that was simultaneously low enough to attract customers and high enough to recoup the equipment's cost before it required replacement.

So, is customer ownership of the local loop inevitably, and unacceptably, unfair to the incumbent? Probably not, for at least the following reasons.

(1) First, as explained above, customer ownership of the local loop is only conceivably unfair to the incumbent in the cases of loops that have not been fully depreciated, and even for those, it is only unfair in the amount that has not been depreciated. It is difficult to find depreciation data that separate subscriber plant from inter office plant for all LECs. However, NYNEX, Pacific Bell, and Southwestern Bell (now SBC Communications, Inc.) separately report inter office and subscriber investment. According to 1994 Theoretical Reserve Studies filed with the FCC, the gross book value of the metallic cable subscriber plant of these three RBOCs was $\$ 22,187,045,000$, and their depreciation reserve was $\$ 10,161,821,000$. Thus, the metallic cable in their 
subscriber plant has been approximately $46 \%$ depreciated. ${ }^{24}$ These figures are probably reasonably representative of all LECs, for NYNEX serves an area where population growth has been slow and so depreciation is probably relatively high, while SBC and Pacific Bell serve areas where population growth has been relatively rapid and so depreciation is probably relatively low. In particular, between 1970 and 1993, population growth in the states served by NYNEX, Pacific Bell and SBC has averaged $1.37 \%$ per year, while the population growth of the entire United States has averaged $1.17 \% .{ }^{25}$ If population growth is directly correlated with new customer lines, then it is likely that the average depreciation for the entire U nited States is somewhat higher than the $46 \%$ depreciation for these LECs, for it is likely that newer local loops are less depreciated than older ones. The above worst case scenario-a nation-wide $54 \%$ write-off of local loop construction cost-assumes that no customers will purchase their existing local loops; this is an extremely conservative assumption.

(2) Second, it is possible that customers will choose to purchase from the incumbent exactly those local loops that have not been fully depreciated-in which case the incumbent will, of course, recover all of its construction costs. Alternatively, it is possible that customers will choose to purchase some loops that have not been fully depreciated and others that have been fully depreciated, and that the aggregate price will include recovery of all undepreciated costs. ${ }^{26}$

\footnotetext{
${ }^{24}$ Cited in Baseman, K.C. \& Van Gieson, H. "Depreciation Policy in the Telecommunications Industry: Implications for Cost Recovery by the Local Exchange Carriers." MiCRA, Inc., December, 1995, Table 9, p. 18.

${ }^{25}$ Population figures are from the 1994 Statistical Abstract of the United States.

${ }^{26} \mathrm{If}$ customer ownership of the local loops is mandated, the issue of purchase price of existing local loops will inevitably arise. If the price is restricted to the undepreciated amount of each customer's local loop, then some loops will be free and some will be relatively expensive, and averaging will be impossible. Alternatively, if the price is restricted to the average undepreciated loop cost, then the averaging suggested in the text is considerably more plausible, and may give the incumbent a competitive advantage in selling loops. I deally, loop construction will be competitive, and the incumbent will choose a price based on competitive considerations (with a ceiling of their total undepreciated loop construction costs).
} 
(3) Third, it is likely that once the decision is made that customers must own their local loops, ${ }^{27}$ there will be a time period of several years during which the change of ownership will occur. Such a time period is desirable to allow for the creation of competition in an industry-local loop construction-that has been dominated by local exchange carriers for nearly 100 years. It will also provide incumbents with several years to write-off undepreciated local loops, and to minimize the number of local loops they may have to write off.

(4) Fourth, many customers who choose not to purchase their existing copper loops from the incumbent may, nevertheless, purchase other loops from the incumbent. This does not directly reduce the write-off the incumbent takes, but the incumbent's profit from selling a new-presumably higher bandwidth, and probably higher priced-loop would certainly soften the blow. This is probably not a "pie-in-the-sky" argument because the incumbent will likely have a significant competitive advantage over competitive entrants: it will have both name recognition and years of experience in loop construction; it may also have significant economies of scale.

(5) Finally, it is possible to question whether requiring the incumbent to write off the undepreciated cost of loop construction actually constitutes unfairness. For, on the one hand, the incumbent has been required by regulators (or, the incumbent has agreed with regulators) to depreciate the loop over long periods. On the other hand, the incumbent has received, in return for regulation, monopoly status that has provided a cost-plus operating environment. The median allowed returns on rate base for all LECs in all states were $11.44 \%$ in $1988,11.24 \%$ in $1989,11.21 \%$ in 1990 ,

\footnotetext{
${ }^{27}$ This assumes that customer ownership of the local loop will be mandatory and universal; must it be so? Certainly, it is possible for some customers to own their local loops and others to rent them. However, such a scenario will solve the problems of interconnection only to the extent that customers own their local loops: if LECS own some of their customers' local loops, then the issue of their "renting" those loops to competitors will remain-as will the issue of how to price such rental. In addition, ancillary advantages of customer ownership of the local loop, such as a competitive loop construction industry, will be greatly diminished.
} 
$10.95 \%$ in $1991-2,10.64 \%$ in $1993-4$, and $10.55 \%$ in 1994 ; the median earned returns on rate base were $10.76 \%$ in $1988,10.72 \%$ in $1989,10.84 \%$ in $1990,10.75 \%$ in $1991-2$, $10.39 \%$ in 1993 , and $9.08 \%$ in $1994 .^{28}$ These numbers are consistently above their contemporary prime interest rates, which were $10.5 \%$ at the ends of 1988 and 1989, $10.0 \%$ at the end of $1990,6.5 \%$ at the end of $1991,6.0 \%$ at the ends of 1992 and 1993 , and $8.5 \%$ at the end of $1994 .{ }^{29}$ Thus, a bank would have earned a higher return on its capital by investing it in a telephone company under rate of return regulation than by lending it to its most credit-worthy customers.

Finally, it is difficult or impossible to quantify potential losses to the incumbent from undepreciated, unpurchased local loops, but it is possible to establish the limits of such losses. The worst case scenario for the incumbent would result from a decision to convert to customer ownership of local loops in X years; whichever loops the incumbent had not sold and had not fully depreciated would simply be losses to the incumbent. This scenario is arguably unfair to incumbents, but it provides them with incentive to creatively minimize their losses from unsold local loops. The best case scenario for the incumbent would result from a decision to compensate the incumbent, on a dollar for dollar basis, for all undepreciated portions of all unsold local loops. ${ }^{30}$ This scenario is certainly not unfair to the incumbent, but it encourages inefficiency by eliminating all incentive for selling existing local loops. It is likely that the former scenario is preferable to the latter, primarily because it is market based, and therefore provides incumbents with the incentive to minimize their losses from unsold local loops.

\footnotetext{
${ }^{28}$ The median allowed and median earned returns were calculated from data in NARUC's Annual Report on Utility and Carrier Regulation, for 1988, 1989, 1990, 1991-2, 1993-4, and 1994-5. In all years, data on earned rates of return were available for only about 20 states.

${ }^{29}$ Prime rate data are from the Federal Reserve Bulletin, and the Standard \& Poor Statistical Service.

${ }^{30}$ In this case, of course, the dollars for this compensation must come from somewhere. There are multiple possibilities, including general tax revenues, a telecommunication equipment tax, a telecommunication usage tax, etc. This issue is similar to that of the source of funds to support universal service; its solution is beyond the scope of this paper.
} 


\subsection{Takings}

The Fifth Amendment of the Constitution of the United States prohibits the government from taking private property without compensatory payment: “. . . nor shall private property be taken for public use, without just compensation." In the past, this has been considered relevant largely to the right of eminent domain, and to the condemnation of property for use by a public highway, for example. ${ }^{31}$ M ore recently, however, there have been suggestions that regulation might, in some-perhaps most-cases, constitute a form of taking. ${ }^{32}$ In the best known recent case on takings, the state of South Carolina was required to fully compensate the owner of two parcels of land when it completely forbade construction of new homes close to the beach. The U.S. Supreme Court ruled that the state was required to pay the property's owner the full value of his land. ${ }^{33} \mathrm{H}$ owever, compensation was required only because South Carolina imposed a completelimitation on Lucas' use of his land. ${ }^{34}$

In telephony, Bell Atlantic and other Regional Bell Operating Companies claimed that the FCC's requirements of physical co-location-the provision of space in an RBOC's central office for equipment of a competitor, in order to facilitate interconnection-violated the Fifth Amendment's takings clause. ${ }^{35}$ The U.S. Court of Appeals vacated the portions of the FCC orders requiring physical co-location, but not on Fifth Amendment grounds. Rather, they ruled that the FCC had no authority, under the Communications Act of 1934 (as amended) to impose physical co-location. They pointed out that, “The Tucker Act, 28 U.S.C. @ 1491(a)(1), vests exclusive jurisdiction over takings claims that exceed $\$ 10,000$ in controversy, as this

\footnotetext{
${ }^{31}$ E pstein, R.A. Takings: Private Property and the Power of Eminent Domain. Cambridge, MA: Harvard University Press, 1985.

${ }^{32}$ See, for example, Epstein, R.A. Simple Rules for a Complex World. Cambridge, MA: Harvard University Press, 1995, pp. 130-137.

${ }^{33}$ Lucas v. South Carolina Coastal Council, 112 S. Ct. 2886 (1992).

${ }^{34}$ E pstein, R.A. op. cit., p. 130.

${ }^{35}$ Bell Atlantic Telephone Companies, et al., v. FCC; case no. 92-1619.
} 
one obviously does, in the Unites States Claims Court." ${ }^{136}$ N evertheless, Pacific Bell and other RBOCs have recently argued before the same U.S. Court of Appeals ${ }^{37}$ that the FCC's virtual co-location orders are not significantly different from its (vacated) physical co-location orders, in that they represent a taking of property under the Fifth Amendment. ${ }^{38}$

The theory of regulatory takings is complex and has only begun to be considered by the courts; a complete treatment of regulatory takings is beyond the scope of this paper. It is possible, however, that mandated customer ownership of the local loop could be considered unconstitutional, under the Fifth Amendment, on the grounds that some undepreciated local loops must be abandoned by their owner. This possibility appears remote, given the long tradition of accepting regulation as legal:

The modern view is to say that government regulation of use is not a taking, for which compensation is payable, unless and until government restrictions go "too far." [footnote omitted] Yet it now appears that this point is never quite reached unless the state imposes a complete limitation on land use. As long as any beneficial use is left to the owner of the land, the courts will not inquire into the reasons for the regulation or demand compensation for the loss of value that the restrictions impose. ${ }^{39}$

In addition, if regulatory takings should become an accepted judicial doctrine, it is likely that customer ownership of the local loop is not the only policy that would require significant reconsideration.

\subsection{J ointly Owned Portions of Loops}

At least since the 1970s, telephone companies have realized that there are cases in which it is cost-effective to increase the use of electronics in order to decrease the use of wire. In particular, Digital Loop Carrier systems have been used to time-multiplex voice traffic from hundreds of local loops onto a single pair of wires or optical fiber (they are then de-

${ }^{36} 24$ F.3d 1441 (1994), note 1.

${ }^{37}$ Pacific Bell et al. v. FCC, consolidated cases beginning at 94-1547.

38“In Court Argument, Bell Companies Question Constitutionality of Virtual Collocation [sic] Rules." Telecommunications Reports October 23, 1995.

${ }^{39}$ Epstein, R.A. op. cit., p. 130. 
multiplexed at the central office). How can customers own their local loops, when not all of "their" local loop is theirs? This is not a new problem: many home owners own part of their housing unit individually, and part of it jointly. Condominium law governs just how such arrangements are made, and protects both the individual owners and the condominium association, which owns the common areas (such as the roof, the basement, hallways, etc.); owners of local loops that are multiplexed over a single Digital Loop Carrier system could form a similar association to govern ownership of their local loops.

Another relevant model is used with undersea cables and telecommunication satellites: each owner is guaranteed an indefeasible right of use (IRU) for a certain portion of the cable's or the satellite's capacity. ${ }^{40} \mathrm{~A}$ third model is provided by the joint ownership agreements often used when multiple companies own an oil pipeline and a portion of the pipeline's capacity.

\subsection{Rental Property}

How can customer ownership of local loops deal with rental property? Can renters of property be expected to purchase the local loops that are (at least in the wireline case) physically connected to the property, and that can't follow their owner when that owner's lease expires? This issue will be dealt with separately for commercial and for residential tenants.

It is common for commercial tenants to make improvements to leased premises, although they know that they cannot take those improvements with them, should they move. When a commercial tenant sells its business, it might expect to recoup the cost of the loop, if the loop has any value to the buyer. But even a tenant who does not sell its business could perhaps negotiate with the property's owner for a contribution to the cost of building the loop, depending on the quality and general value of the loop the tenant plans to construct.

\footnotetext{
${ }^{40}$ See, for example, Goldberg, H. "One-Hundred and Twenty Years of International Communications." Federal Communications Law J ournal, 27:1 (J an., 1985), p. 139.
} 
Alternatively, the owner of commercial property might install loops as a means of attracting tenants who value those loops (for example, owners often install indoor plumbing to attract tenants who value it). A final option is for the tenant to write off loop construction as a cost of doing business-just as the tenant would write off the cost of upgrading a building's lighting or electrical service, if that were necessary. Even a loop that cost several thousand dollars would hardly be a large expense, in most cases.

For residential tenants, the options are fewer. It is probably most reasonable for the property's owner to own the loops. This is unlikely to be a prohibitive cost, for multiple loops in a single building would likely cost far less than the same number of loops, one to a building. At the very least, the property owner could take advantage of time multiplexing, with no concern for joint ownership of parts of the loop. This is similar to the landlord's provision of electricity and plumbing in residential property: even if it is legal for a landlord to not provide this infrastructure in rental property, it clearly increases the value of the property to tenants when the landlord does provide it.

\subsection{Loop Maintenance}

Even if a customer is convinced that owning his or her loop will provide significant benefit, how will that customer be convinced that it is worth while to maintain his or her loop? There are two parts to this answer; the issue may perhaps be compared with the issue of inside wiring. First, it is likely that loop maintenance is not a major issue: local loops do not wear out on a regular basis, because el ectrons do not cause wear to copper wires or coaxial cable, nor do photons cause wear to optical fiber. Second, it is likely that loop construction companies will be willing to provide maintenance contracts al ong with construction agreements, since most customers will be unlikely to possess the skill or the desire to be responsible for loop maintenance. 


\section{Summary and Conclusions}

If there are multiple, non-overlapping providers of telephony, interconnection among them will increase the value of the network to customers. However, when one of the providers owns all or most of the local loops, and-because of the high cost of their duplication-the other service providers must "rent" the local loops of their customers from the incumbent, it is difficult to determine a price for interconnection which is fair to both the owner and the renter of the infrastructure. For, if the rental price is too high, then the renter - the competitive entrant-will be unable to compete, regardless of its inherent efficiency. On the other hand, if the rental price is too low, then the incumbent will be subsidizing the entrant. This paper has shown, however, that if customers own their local loops, virtually all of the difficult problems involved in pricing interconnection disappear. Customer ownership of the local loops means that entrants will not need to rent local loops from the incumbent, and so interconnection can be negotiated in a simple and straightforward manner.

\section{Bibliography}

Albon, R. "I Interconnection Pricing: An Analysis of the Efficient Component Pricing Rule." Telecommunications Policy 18(5), 1994, pp. 414-420.

Arellano, M. “Exploiting the LECs' Achilles' Heel.” Telecom Strategy Letter, J uly, 1995, pp. 81-85.

Baumol, W.J . “Direct Testimony of William J . Baumol of Behalf of AT\&T.” Case 92-C-0665. 1994.

Baumol, W.J . \& Sidak, J .G. "The Pricing of I nputs Sold to Competitors." The Yale J ournal on Regulation, 11(1), 1994, pp. 171-202.

Baumol, W.J . \& Sidak, J .G. Toward Competition in Local Telephony. Cambridge, MA: The MIT Press, 1994.

Brock, G.W. The Telecommunications I ndustry: The Dynamics of Market Structure Cambridge, MA: Harvard University Press, 1981.

Brock, G.W. "Interconnection and Mutual Compensation With Partial Competition." In The E conomics of I nter connection, Teleport Communications Group, 1995.

Economides, N. and White, L.J. Access and Interconnection Pricing: How Efficient is the 
'Efficient Component Pricing Rule'?" Antitrust Bulletin, 40(3), 1995, pp 557-579.

Epstein, R.A. Simple Rules for a Complex World. Cambridge, MA: Harvard University Press, 1995.

Epstein, R.A. Takings: Private Property and the Power of Eminent Domain. Cambridge, MA: Harvard University Press, 1985.

Goldberg, H. "One-Hundred and Twenty Years of I nternational Communications." Federal Communications Law J ournal, 27:1 (J an., 1985), pp. 131-154.

Grieve, W. \& Levin, S.L. "E conomic Principles and Pricing Rules for Local Network Interconnection and Network Component Unbundling With Applications for New Zealand." Paper presented at International Tel ecommunications Society I nterconnection Workshop, 10-12 April 1995, Wellington, N.Z.

J ohnson, L. Toward Competition in CableTelevision. Cambridge, MA: MIT Press, 1994.

Laffont, J.-J . and Tirole, J . "Creating Competition Through Interconnection: Theory and Practice." Paper presented at International Telecommunications Soci ety I nterconnection Workshop, 10-12 April 1995, Wellington, N.Z.

Patterson, R., Savin, B. and Davies, M. "Light-Handed Regulation of Telecommunications in New Zealand: The New Frontier?" Paper presented at International Telecommunications Society I nterconnection Workshop, 10-12 April 1995, Wellington, N.Z.

Saunders, M. "Telecommunications Regulation in New Zealand." Telecommunications Policy 18(6), 1994, pp. 495-496.

Schechter, P.B. "Telecommunication in New Zealand: Competition, Contestability and Interconnection." Submitted to Pacific Telecommunication Review.

Schechter, P.B. "Customer Ownership of the Local L oop: Its Effects on Competition in Telephony." To be presented at the Eleventh World Conference of the International Telecommunications Society, J une, 1996.

U.S. Bureau of the Census, Statistical Abstract of the United States: 1995 (115th edition). Washington, D.C., 1995.

Walker, D. \& Solomon, J . "The I nterconnection I mperative: E pluribus unum." Telecommunications Policy, 17(4), 1993, pp. 257-280. 